\title{
Spinal mepivacaine with fentanyl for outpatient knee arthroscopy surgery: a randomized controlled trial
}

\section{Mépivacaïne rachidienne additionnée de fentanyl pour une arthroscopie du genou en ambulatoire: une étude randomisée contrôlée}

\author{
Dermot O'Donnell, MD • Baskar Manickam, MD • Anahi Perlas, MD • \\ Reena Karkhanis, MD • Vincent W. S. Chan, MD • Khalid Syed, MD • \\ Richard Brull, MD
}

Received: 26 June 2009/ Accepted: 13 October 2009/Published online: 24 October 2009

(C) Canadian Anesthesiologists' Society 2009

\begin{abstract}
Background The foremost limitation of local anesthetic solutions for spinal anesthesia in the outpatient setting is prolonged motor blockade and delayed ambulation. The purpose of this study was to determine if the addition of intrathecal fentanyl to low-dose spinal mepivacaine provides adequate anesthesia with shorter duration of functional motor blockade for ambulatory knee surgery compared with spinal mepivacaine alone.

Methods Following institutional review board approval and informed consent, 34 patients undergoing unilateral knee arthroscopy were enrolled in this study. The patients were randomly assigned to receive either $30 \mathrm{mg}$ of isobaric mepivacaine $1.5 \%$ plus fentanyl $10 \mu \mathrm{g}(M+F$ group) or $45 \mathrm{mg}$ of isobaric mepivacaine $1.5 \%$ alone ( $M$ group) intrathecally. Postoperatively, the times to achieve sensory
\end{abstract}

Presented in part at the American Society of Regional Anesthesia and Pain Medicine Annual Spring Meeting, April 30-May 3, 2009, Phoenix, Arizona.

D. O’Donnell, MD - B. Manickam, MD · A. Perlas, MD ·

R. Karkhanis, MD · V. W. S. Chan, MD · R. Brull, MD (ه) Department of Anesthesia and Pain Management, Toronto

Western Hospital, University Health Network, Mc Laughlin Pavilion 2-405, 399 Bathurst Street, Toronto, ON M5T-2S8,

Canada

e-mail: richard.brull@uhn.on.ca

K. Syed, MD

Department of Orthopedic Surgery, Toronto Western Hospital, University Health Network, Toronto, ON, Canada block regression to the S1 dermatome and to attain functional motor block recovery enabling ambulation were recorded. All assessments were blinded.

Results The time to completion of Phase I recovery was shorter in the $M+F$ group (104.6 $\pm 28.4 \mathrm{~min})$ than in the $M$ group (129.1 \pm 30.4 min; $P=0.023)$. Regression of sensory blockade to $S 1$ was earlier in the $M+F$ group $(118.4 \pm 53.5 \mathrm{~min})$ than in the $M$ group (169.7 \pm 38.9 min; $P=0.003)$. Patients in the $M+F$ group (176.4 \pm $40.3 \mathrm{~min})$ were able to ambulate significantly earlier than those in the $M$ group $(205.6 \pm 31.4 \mathrm{~min} ; P=0.025)$. No cases of transient or persistent neurological dysfunction were noted.

Conclusions When compared with $45 \mathrm{mg}$ isobaric mepivacaine $1.5 \%$, an intrathecal dose of $30 \mathrm{mg}$ isobaric mepivacaine $1.5 \%$ plus $10 \mu \mathrm{g}$ fentanyl produces reliable anesthesia, hastens block regression, shortens stay in Phase $I$ recovery, and enables earlier ambulation for patients undergoing unilateral knee arthroscopy (Registration no. NCT00803725).

\section{Résumé}

Contexte Un bloc moteur prolongé et une ambulation retardée sont les restrictions les plus importantes à l'utilisation de solutions d'anesthésiques locaux pour la rachianesthésie dans un contexte ambulatoire. L'objectif de cette étude était de déterminer si l'ajout de fentanyl intrathécal à une faible dose de mépivacaïne rachidienne procurait une anesthésie adaptée avec une durée plus courte du bloc moteur fonctionnel lors de chirurgie ambulatoire du genou par rapport à une injection rachidienne de mépivacaine seule. 
Méthode Après avoir obtenu l'approbation du comité d'éthique indépendant et le consentement éclairé des patients, 34 patients subissant une arthroscopie unilatérale $d u$ genou ont pris part à cette étude. Les patients ont été aléatoirement répartis à recevoir soit $30 \mathrm{mg}$ de mépivacaine isobare $1,5 \%$ plus $10 \mu \mathrm{g}$ de fentanyl (groupe $M+F)$ ou $45 \mathrm{mg}$ de mépivacaïne isobare $1,5 \%$ seule (groupe M) par voie intrathécale. Après l'opération, nous avons enregistré les temps requis jusqu'à régression du bloc sensitif au dermatome S1 et jusqu'à une récupération du bloc moteur fonctionnel suffisante à permettre l'ambulation. Toutes les évaluations ont été réalisées en aveugle. Résultats Il a fallu moins de temps jusqu'à la réalisation d'une récupération de Phase I aux patients dans le groupe $M+F(104,6 \pm 28,4$ min $)$ qu'à ceux du groupe $M$ $(129,1 \pm 30,4 \mathrm{~min} ; P=0,023)$. La régression du bloc sensitif jusqu'à $S 1$ est survenue plus tôt dans le groupe $M+F \quad(118,4 \pm 53,5 \mathrm{~min})$ que dans le groupe $M$ $(169,7 \pm 38,9 \mathrm{~min} ; P=0,003)$. Les patients du groupe $M+F(176,4 \pm 40,3 \mathrm{~min})$ ont été capables de marcher significativement plus tôt que ceux du groupe $M$ (205,6 \pm 31,4 min; $P=0$,025). Aucun cas d'atteinte neurologique provisoire ou permanente n'a été observé.

Conclusion Comparativement à une dose de $45 \mathrm{mg}$ de mépivacaïne isobare 1,5\%, une dose intrathécale de $30 \mathrm{mg}$ de mépivacaine isobare 1,5\% additionnée de $10 \mu \mathrm{g}$ de fentanyl procure une anesthésie fiable, accelère la régression du bloc, raccourcit le séjour en récupération de Phase I et permet une ambulation plus précoce des patients subissant une arthroscopie unilatérale du genou (No. d'enregistrement NCT00803725).

\section{Introduction}

The foremost limitation of many local anesthetic solutions for spinal anesthesia in day-case surgery is prolonged motor blockade and subsequent delay in ability to ambulate. ${ }^{1-4}$ Local anesthetics with fast onset, fast offset, and minimal adverse effects have been an area of interest for anesthesiologists, surgeons, and hospital administrators alike in order to ensure timely discharge following day surgery. Ambulation is the most important postoperative milestone affecting a patient's home readiness and ultimately discharge from hospital. ${ }^{5,6}$

Lidocaine has a favourable pharmacokinetic profile for ambulatory surgery, but its use is limited by an unacceptably high incidence of transient neurological symptoms (TNS) ${ }^{7-9}$ Mepivacaine is physicochemically similar to lidocaine and widely used for brachial plexus anesthesia, but its application in spinal anesthesia has been relatively limited to date. In a previous dose-response study, Zayas et al. demonstrated that a reduction in the intrathecal dose of mepivacaine $1.5 \%$ from 45 to $30 \mathrm{mg}$ significantly reduced the duration of motor blockade by nearly $20 \%$, but almost one-third of patients who received $30 \mathrm{mg}$ experienced intraoperative pain or discomfort. ${ }^{10}$

Our objective was to determine if low-dose spinal mepivacaine combined with fentanyl would produce adequate surgical anesthesia for ambulatory knee arthroscopy with faster recovery and discharge compared with standard dose mepivacaine alone. We hypothesized that the addition of intrathecal fentanyl to low-dose spinal mepivacaine would provide adequate surgical anesthesia and hasten the regression of motor blockade allowing earlier ambulation than administering standard dose mepivacaine alone.

\section{Methods}

This study was registered at clinicaltrials.gov (Registration no. NCT00803725). After obtaining institutional review board approval and written informed consent, 34 patients classified as ASA physical status I-III undergoing unilateral knee arthroscopy at the Toronto Western Hospital, Toronto, Ontario Canada (247-bed tertiary care teaching hospital affiliated with the University of Toronto), were prospectively enrolled. The patients were randomly assigned by a computer-generated randomization table and a sealed envelope technique to receive either $30 \mathrm{mg}$ of mepivacaine $1.5 \%$ combined with $10 \mu \mathrm{g}$ of fentanyl ( $\mathrm{M}+\mathrm{F}$ group) or $45 \mathrm{mg}$ of mepivacaine $1.5 \%$ alone (M group) intrathecally. These agents are widely used and accepted for neuraxial administration. Patients who were incapable of giving informed consent, those with known hypersensitivity to amide local anesthetics or opioids, and those with contraindications to spinal anesthesia were excluded. All study personnel and participants were blinded to the treatment assignment for the duration of the study.

On arrival to the operating room, the patients received oxygen at a rate of $6-8 \mathrm{~L} \cdot \mathrm{min}^{-1}$ via facemask and were monitored with continuous pulse oximetry, electrocardiography, and noninvasive blood pressure prior to administration of medication and at 5-min intervals thereafter. An intravenous infusion of normal saline was started, and the patients received midazolam $0.03-0.04 \mathrm{mg} \cdot \mathrm{kg}^{-1}$ before positioning for lumbar puncture. Lumbar puncture was performed in the sitting position with the patient immediately returned to supine on completion of the spinal injection. The intrathecal injectate was prepared by an experienced regional anesthesiologist who performed the lumbar puncture using a 25G $90 \mathrm{~mm}$ Whitacre needle (Benlan Inc., Oakville, ON, Canada) positioned midline at the L3-4 or L4-5 interspace with orifice directed cephalad.

Following the administration of the spinal anesthetic, a trained research assistant blinded to group allocation 
performed all assessments. Sensory perception to pinprick stimulus was tested every 2 min using a $22 \mathrm{G}$ hypodermic needle until the dermatomal level had stabilized for four consecutive tests. Peak sensory block height and the time to achieve this level were recorded.

If requested, intraoperative anxiolysis was provided with a propofol infusion $25-50 \mu \mathrm{g} \cdot \mathrm{kg}^{-1} \cdot \mathrm{min}^{-1}$ titrated to maintain verbal contact. Patients expressing pain or discomfort were treated with an intravenous bolus of fentanyl $0.25-0.5 \mu \mathrm{g} \cdot \mathrm{kg}^{-1}$. General anesthesia would be administered in the event of inadequate surgical anesthesia. All medications were recorded. Intraoperatively, the patient was in the knee arthroscopy position (supine with the operative knee flexed).

Postoperatively, motor block was assessed every $10 \mathrm{~min}$ using the Modified Bromage Scale scored as follows: $0=$ no motor block; $1=$ hip blocked; $2=$ hip and knee blocked; $3=$ no movement, complete motor block. Pinprick testing was performed every $10 \mathrm{~min}$ until sensory block regression to the $\mathrm{S} 1$ dermatome was appreciated and every $30 \mathrm{~min}$ thereafter until hospital discharge. The times to completion of Phase I recovery (Modified Aldrete Score $\geq 9$; Appendix 1), ${ }^{11}$ first analgesic request, first urination, first ambulation, completion of Phase II recovery (Modified Post-Anesthesia Discharge Scoring System [PADSS] score $\geq 9),{ }^{12}$ and hospital discharge were assessed every $10 \mathrm{~min}$ and recorded. The time to first instance of ambulation was defined as the duration of time from intrathecal injection to achieving PADSS ambulation score $=2$ points (steady gait/no dizziness). ${ }^{12}$ All times were recorded from the point of administration of the spinal anesthetic. The incidence of hypotension (systolic blood pressure $<90 \mathrm{mmHg}$ ), bradycardia (heart rate $<50$ beats $\cdot \min ^{-1}$ and symptomatic), nausea/vomiting, and pruritis were also recorded. Patients were discharged home only after fulfilling the modified PADSS criteria for day surgery (Appendix 2). ${ }^{12}$ Postoperative analgesia was determined by the surgical team and may or may not have included non-steroidal anti-inflammatory drugs.

Follow-up telephone calls were placed at $48-72 \mathrm{hr}$ following discharge using a standardized questionnaire to evaluate the incidence of side effects since discharge, including dizziness, nausea, vomiting, pruritis, and disturbances in urination and/or defecation. Patient satisfaction with the anesthetic received and the overall anesthesia experience was also assessed using a ten-point verbal response scale $(0=$ not satisfied; $10=$ completely satisfied). Symptoms consistent with postdural puncture headache, TNS, or persistent neurological dysfunction were sought. Transient neurological symptoms were defined as new onset lower back pain or dysesthesia radiating bilaterally to the buttocks and lower extremities that began within the first $24 \mathrm{hr}$ after surgery and lasted up to a week followed by spontaneous resolution. ${ }^{9}$ Back pain that did not meet these criteria was not viewed as TNS.

Statistical analysis

Our primary outcome was time to complete motor block regression, defined as the duration of time from intrathecal injection to Modified Bromage Scale score of 0. Based on a previously published dose-response study for spinal mepivacaine,${ }^{10}$ we hoped to demonstrate a $20 \%$ reduction in the duration of motor blockade by comparing the addition of $10 \mu \mathrm{g}$ fentanyl to $30 \mathrm{mg}$ mepivacaine $1.5 \%$ with the administration of $45 \mathrm{mg}$ mepivacaine $1.5 \%$ alone. A sample size of 17 patients was required in each group in order to detect a $20 \%$ reduction in the duration of motor blockade with $\alpha=0.05$ and $80 \%$ power. Statistical analyses were performed using the programs, Systat 7.0 (SPSS Inc, Chicago, IL, USA) and MedCalc version 9.3.2.0 (MedCalc Software, Mariakerke, Belgium). Tests of significance included the unpaired $t$ test and the Mann-Whitney test of ranks for parametric and non-parametric testing of continuous variables, respectively. The Chi square or the Fisher's exact test was used to analyze categorical data. Results were analyzed on an intent-to-treat basis. Statistical significance was established at $P<0.05$.

\section{Results}

The study was conducted from September 1, 2008 to January 31,2009 . Eight of the 42 patients screened were excluded after refusing to participate. Thirty-four patients, 17 in each group, were enrolled in the study. There were no patient dropouts, no protocol deviations, and the data from all 34 subjects are reported.

Patient characteristics were similar between groups and surgical anesthesia was achieved in all patients (Table 1).

It was evident very early during the course of data collection that patients in both groups had reached a score of 0 on the Modified Bromage Scale at the initial postoperative assessment measured immediately upon arrival in Phase I recovery. Since intraoperative motor function assessment was not feasible, it was not possible to faithfully measure the duration of time from intrathecal injection to Modified Bromage Scale score of 0 . We therefore abandoned Modified Bromage Scale data collection for the remainder of the study in favour of measuring the time to the first instance of ambulation. Patients in the $\mathrm{M}+\mathrm{F}$ group were able to ambulate significantly earlier than those in the $\mathrm{M}$ group (Table 2).

The times to block stabilization and peak block height were similar between groups (Table 2). Mean intraoperative propofol (M: $24.7 \pm 55.4 ; \mathrm{M}+\mathrm{F}: 55.3 \pm 75.0 \mathrm{mg}$; 
Table 1 Patient characteristics

\begin{tabular}{lll}
\hline & Mepivacaine + fentanyl $(n=17)$ & Mepivacaine $(n=17)$ \\
\hline Gender (male/female) & $9 / 8$ & $8 / 9$ \\
Age $(\mathrm{yr})$ & $50.5(15.9)$ & $42.7(14.7)$ \\
Height $(\mathrm{m})$ & $1.7(0.2)$ & $1.7(0.1)$ \\
Weight $(\mathrm{kg})$ & $81.0(17.7)$ & $94.0(25.9)$ \\
BMI & $30.2(8.5)$ & $33.0(8.7)$ \\
ASA physical status & & \\
I & $11(64.7 \%)$ & $11(64.7 \%)$ \\
II & $3(17.7 \%)$ & $5(29.4 \%)$ \\
III & $3(17.7 \%)$ & $1(5.9 \%)$ \\
Peak sensory block height & & \\
T12 & $13(76.5 \%)$ & $11(64.7 \%)$ \\
T10 & $0(0.0 \%)$ & $1(5.9 \%)$ \\
L1 & $4(23.5 \%)$ & $5(29.4 \%)$ \\
\hline
\end{tabular}

Table 2 Block characteristics

\begin{tabular}{|c|c|c|c|c|c|}
\hline Time to $(\mathrm{min})$ & Mepivacaine + fentanyl & Mepivacaine & Difference & $95 \% \mathrm{CI}$ & $P$ value \\
\hline Peak sensory block height stabilization & $9.9(1.1)$ & $10.5(1.4)$ & 0.6 & -0.3 to 1.5 & 0.180 \\
\hline Completion of Phase I recovery & $104.6(28.4)$ & $129.1(30.4)$ & 24.5 & 4.0 to 45.1 & 0.023 \\
\hline Sensory block regression to $\mathrm{S} 1$ & $118.4(53.5)$ & $169.7(38.9)$ & 51.3 & 18.6 to 84.0 & 0.003 \\
\hline First analgesic request & $122.1(70.8)$ & $127.3(52.8)$ & 5.2 & -38.4 to 48.8 & 0.855 \\
\hline Completion of Phase II recovery & $157.2(69.9)$ & $169.4(63.3)$ & 12.2 & -34.3 to 58.9 & 0.599 \\
\hline First ambulation & $176.4(40.3)$ & $205.6(31.4)$ & 29.2 & 4.0 to 54.4 & 0.025 \\
\hline First urination & $192.2(36.4)$ & $213.5(34.3)$ & 21.3 & -3.4 to 46.0 & 0.089 \\
\hline Hospital discharge & $226.4(37.4)$ & $242.5(39.3)$ & 16.1 & -10.7 to 42.9 & 0.229 \\
\hline
\end{tabular}

Values are presented as mean (standard deviation) and represent time in minutes lapsed from intrathecal injection to specified milestone CI confidence interval

$P=0.19)$ and intravenous fentanyl (M: $8.8 \pm 19.6$; $\mathrm{M}+\mathrm{F}: 4.4 \pm 13.2 \mu \mathrm{g} ; P=0.45)$ consumption did not differ between groups.

The time from intrathecal injection to completion of Phase I recovery was shorter in the $\mathrm{M}+\mathrm{F}$ group than in the $\mathrm{M}$ group (Table 2). The time to sensory block regression to the $\mathrm{S} 1$ dermatome was shorter in the $\mathrm{M}+\mathrm{F}$ group (Table 2). The times to first analgesic request, first urination, completion of Phase II recovery, and home discharge did not differ between groups (Table 2).

Patient satisfaction with the anesthetic received and the overall anesthesia experience was rated as 10 out of 10 in $97 \%$ of patients treated. The median satisfaction score reported was 10 in the $\mathrm{M}+\mathrm{F}$ group and 9 in the $\mathrm{M}$ group (range: $9-10 ; P=1.00$ ).

Nausea, vomiting, or pruritis were not reported in any patient studied. All patients urinated spontaneously without intervention. No incidences of hypotension, bradycardia, postdural puncture headache, TNS, or persistent neurological dysfunction were reported.

\section{Discussion}

With the shift away from costly perioperative hospital admissions and toward ambulatory surgery, providing reliable short-lived spinal anesthesia to outpatients undergoing knee arthroscopy can be a challenging endeavour. While $45 \mathrm{mg}$ mepivacaine $1.5 \%$ had been the spinal anesthetic of choice for ambulatory knee arthroscopy at our home institution, the common goal of expedited hospital discharge commands continual re-evaluation of our regional anesthesia techniques. The results of our present study suggest that $30 \mathrm{mg}$ mepivacaine $1.5 \%$ combined with $10 \mu \mathrm{g}$ fentanyl affords similarly rapid and reliable onset of complete surgical anesthesia when compared with $45 \mathrm{mg}$ mepivacaine $1.5 \%$ alone; however, it also hastens block regression, shortens stay in Phase I recovery, and enables earlier ambulation. We selected ambulation as our clinically important outcome rather than serial postoperative assessments of gross motor function using the Modified Bromage Scale, which was clearly not sensitive enough 
under the present study conditions and is not a reliable indicator of the ability to ambulate or the readiness for discharge. ${ }^{13}$ Indeed, disparities have been demonstrated following spinal anesthesia between the time required for recovery of gross motor function and the time required for recovery of functional balance for ambulation, with functional balance remaining impaired long after motor function recovery was deemed complete. ${ }^{13}$

Lidocaine, traditionally the most widely used local anesthetic agent for ambulatory surgical procedures because of its short duration of action, has been implicated in cases of both temporary and permanent neurological deficits. Recent interest in finding alternatives to lidocaine has been fuelled by an unacceptably high rate of TNS (reportedly up to $32 \%),{ }^{8}$ leading to studies with procaine, ${ }^{14}$ prilocaine, ${ }^{15}$ and dilute bupivacaine, ${ }^{16}$ with or without fentanyl. ${ }^{17}$ While bupivacaine is associated with a lower incidence of TNS $(0-3 \%)$, the prolonged duration of motor blockade and increased risk of urinary retention make bupivacaine less than ideal for outpatient surgery. Since the duration of the local anesthesia is dependent on the dose administered, 1,3,18 lower doses of bupivacaine in spinal anesthesia have also been examined with unsatisfactory results for routine daycase use. $^{17,19-22}$

Chloroprocaine is particularly well suited to ambulatory neuraxial anesthesia, producing a fast onset excellent sensory block. $^{23,24}$ However in the early 1980s, neurological deficits were observed after apparent intrathecal injection of a chloroprocaine solution containing sodium bisulfite intended for epidural administration. ${ }^{25-27}$ Although bisulfite-free formulations of chloroprocaine are available for clinical use and are currently being investigated for outpatient spinal anesthesia with favourable results, ${ }^{28}$ the relative toxicities of this anesthetic and its excipients are not clearly established; therefore, further work is required to clarify the safety profile of preservative-free chloroprocaine for future use. $^{29}$

Despite its favourable pharmacokinetic profile for ambulatory surgery, the popularity of mepivacaine has likely been stunted by its association with TNS. Indeed, a very high incidence (30-37\%) of TNS had been reported using $80 \mathrm{mg}$ of $4 \%$ hyperbaric mepivacaine, ${ }^{30}$ now clinically unavailable. In the largest observational trial to date involving 1,273 patients, the incidence of TNS with $1.5 \%$ isobaric mepivacaine was $6.4 \% .^{31}$ Results from smaller randomized blinded trials have demonstrated rates of TNS ranging from 0 to $7.4 \% .^{10,18,32,33}$ Reported risk factors for the development of TNS include outpatient status, obesity, lithotomy, and knee arthroscopy position. ${ }^{34,35}$ In the present study, no patient reported symptoms consistent with TNS despite some of our enrolled patients having many of the reported risk factors. This finding is consistent with the anecdotal experience at the authors' home institution. Since adopting $1.5 \%$ mepivacaine as the local anesthetic of choice for ambulatory spinal anesthesia in 2005, the authors recall only one reported case of TNS associated with intrathecal mepivacaine. It is possible that the relatively low dose of mepivacaine used in this study and/or the use of fentanyl may protect against the development of TNS; however, this itself will require further investigation.

While our results demonstrate that low-dose spinal mepivacaine with fentanyl can shorten length of stay in Phase I recovery following knee arthroscopy, we were unable to demonstrate earlier discharge from hospital. However, discharge from hospital after day-case surgery is invariably influenced by several other confounding factors, such as the availability of personnel effecting the patient discharge or family members to accompany the patient home. ${ }^{36}$ We may presume, however, that these confounders should have been equally distributed between the two groups in this study.

In summary, our results suggest that the addition of $10 \mu \mathrm{g}$ of fentanyl to $30 \mathrm{mg}$ of isobaric mepivacaine $1.5 \%$ produces reliable spinal anesthesia, hastens block regression, shortens stay in Phase I recovery, and enables earlier ambulation for outpatients undergoing unilateral arthroscopic surgery of the knee when compared with administering $45 \mathrm{mg}$ isobaric mepivacaine $1.5 \%$ alone.

Acknowledgements The authors sincerely thank Doctors Gregory A. Liguori and Richard L. Kahn, The Hospital for Special Surgery, New York for their guidance during the preparation of this study protocol.

Disclosures Dr. Richard Brull is a consultant for B. Braun. Dr. Vincent Chan receives equipment support and honoraria from Philips Medical System, SonoSite, and GE Medical.

Competing interests None declared.

\section{Appendix 1}

Modified Aldrete Score ${ }^{11}$

Activity

Able to move 4 extremities voluntarily or on command 2

Able to move 2 extremities voluntarily or on command 1

Unable to move extremities voluntarily or on command 0

Respiration

Able to breathe deeply and cough freely 2

Dyspnea or limited breathing

Apneic

1

Circulation

$\mathrm{BP} \pm 20 \%$ of pre-anesthetic level

$\mathrm{BP} \pm 20$ to $49 \%$ of pre-anesthetic level 1

$\mathrm{BP} \pm 50 \%$ of pre-anesthetic level 0 


\begin{tabular}{ll} 
Appendix 1 continued & \\
\hline Consciousness & 2 \\
Fully awake & 1 \\
Arousable on calling & 0 \\
Not responding & 2 \\
Oxygen saturation & 1 \\
Able to maintain $\mathrm{O}_{2}$ saturation $>92 \%$ on room air & 0 \\
Needs $\mathrm{O}_{2}$ inhalation to maintain saturation $>90 \%$ & \\
$\mathrm{O}_{2}$ saturation $<90 \%$ even with $\mathrm{O}_{2}$ supplement & \\
\hline
\end{tabular}

\section{Appendix 2}

A modified Post-Anesthesia Discharge Scoring System ${ }^{12}$

\begin{tabular}{lr}
\hline Vital signs & 2 \\
Within $20 \%$ of preoperative value & 1 \\
$20-40 \%$ of preoperative value & 0 \\
$40 \%$ of preoperative value & 2 \\
Ambulation & 1 \\
Steady gait/no dizziness & 0 \\
With assistance & \\
None/dizziness & 2 \\
Nausea/vomiting & 1 \\
Minimal & 0 \\
Moderate & \\
Severe & 2 \\
Pain & 1 \\
Minimal & 0 \\
Moderate & \\
Severe & 2 \\
Surgical bleeding & 1 \\
Minimal & 0 \\
Moderate & \\
Severe &
\end{tabular}

The total score is 10 . Patients achieving a score $\geq 9$ are considered fit for discharge home

\section{References}

1. Urmey WF. Spinal anaesthesia for outpatient surgery. Best Pract Res Clin Anaesthesiol 2003; 17: 335-46.

2. Wong J, Marshall S, Chung F, Sinclair D, Song D, Tong D. Spinal anesthesia improves the early recovery profile of patients undergoing ambulatory knee arthroscopy. Can J Anesth 2001; 48: 369-74.

3. Liu SS, Ware PD, Allen HW, Neal JM, Pollock JE. Dose-response characteristics of spinal bupivacaine in volunteers. Clinical implications for ambulatory anesthesia. Anesthesiology 1996; 85: 729-36.

4. Casati A, Vinciguerra F. Intrathecal anesthesia. Curr Opin Anaesthesiol 2002; 15: 543-51.
5. Schreiner MS, Nicolson SC, Martin T, Whitney L. Should children drink before discharge from day surgery? Anesthesiology 1992; 76: 528-33.

6. Mulroy MF, Salinas FV, Larkin L, Polissar NL. Ambulatory surgery patients may be discharged before voiding after shortacting spinal and epidural anesthesia. Anesthesiology 2002; 97 : 315-9.

7. Freedman JM, Li DK, Drasner K, Jaskela MC, Larsen B, Wi S. Transient neurologic symptoms after spinal anesthesia: an epidemiologic study of 1,863 patients. Anesthesiology 1998; 89: 633-41.

8. Zaric D, Christiansen C, Pace NL, Punjasawadwong Y. Transient neurologic symptoms after spinal anesthesia with lidocaine versus other local anesthetics: a systematic review of randomized, controlled trials. Anesth Analg 2005; 100: 1811-6.

9. Sime AC. AANA journal course: transient neurologic symptoms and spinal anesthesia. AANA J 2000; 68: 163-8.

10. Zayas VM, Liguori GA, Chisholm MF, Susman MH, Gordon MA. Dose response relationships for isobaric spinal mepivacaine using the combined spinal epidural technique. Anesth Analg 1999; 89: $1167-71$.

11. Aldrete JA. The post-anesthesia recovery score revisited. J Clin Anesth 1995; 7: 89-91.

12. Chung F. Discharge criteria-a new trend. Can J Anaesth 1995; 42: 1056-8.

13. Imarengiaye CO, Song D, Prabhu AJ, Chung F. Spinal anesthesia: functional balance is impaired after clinical recovery. Anesthesiology 2003; 98: 511-5.

14. Axelrod EH, Alexender GA, Brown M. Spinal anesthesia and transient neurologic symptoms: procaine is of significantly shorter duration than dilute bupivacaine. Anesthesiology 1998; 89: A47.

15. Pollock JE, Neal JM, Stephenson CA, Wiley CE. Prospective study of the incidence of transient radicular irritation in patients undergoing spinal anesthesia. Anesthesiology 1996; 84: 1361-7.

16. Ben-David B, Levin H, Solomon E, Admoni H, Vaida S. Spinal bupivacaine in ambulatory surgery: the effect of saline dilution. Anesth Analg 1996; 83: 716-20.

17. Ben-David B, Solomon E, Levin H, Admoni H, Goldik Z. Intrathecal fentanyl with small-dose dilute bupivacaine: better anesthesia without prolonging recovery. Anesth Analg 1997; 85: $560-5$.

18. Pawlowski J, Sukhani R, Pappas AL, et al. The anesthetic and recovery profile of two doses (60 and $80 \mathrm{mg}$ ) of plain mepivacaine for ambulatory spinal anesthesia. Anesth Analg 2000; 91: $580-4$.

19. Tarkkila P, Huhtala J, Tuominen M. Home-readiness after spinal anaesthesia with small doses of hyperbaric $0.5 \%$ bupivacaine. Anaesthesia 1997; 52: 1157-60.

20. Borghi B, Stagni F, Bugamelli S, et al. Unilateral spinal block for outpatient knee arthroscopy: a dose-finding study. J Clin Anesth 2003; 15: 351-6.

21. Korhonen AM, Valanne JV, Jokela RM, Ravaska P, Korttila KT. A comparison of selective spinal anesthesia with hyperbaric bupivacaine and general anesthesia with desflurane for outpatient knee arthroscopy. Anesth Analg 2004; 99: 1668-73.

22. Fanelli G, Borghi B, Casati A, Bertini L, Montebugnoli M, Torri $G$. Unilateral bupivacaine spinal anesthesia for outpatient knee arthroscopy. Italian Study Group on Unilateral Spinal Anesthesia. Can J Anesth 2000; 47: 746-51.

23. O'Brien JE, Abbey $V$, Hinsvark $O$, et al. Metabolism and measurement of chloroprocaine, an ester-type local anesthetic. J Pharm Sci 1979; 68: 75-8.

24. Kuhnert BR, Kuhnert PM, Prochaska AL, Perel J, Finster M. Plasma levels of 2-chloroprocaine in obstetric patients and their neonates after epidural anesthesia. Anesthesiology 1980; 53: 21-5. 
25. Ravindran RS, Bond VK, Tasch MD, Gupta CD, Luerssen TG. Prolonged neural blockade following regional analgesia with 2-chloroprocaine. Anesth Analg 1980; 59: 447-51.

26. Reisner LS, Hochman BN, Plumer MH. Persistent neurologic deficit and adhesive arachnoiditis following intrathecal 2-chloroprocaine injection. Anesth Analg 1980; 59: 452-4.

27. Moore DC, Spierdijk J, van Kleef JD, Coleman RL, Love GF. Chloroprocaine neurotoxicity: four additional cases. Anesth Analg 1982; 61: 155-9.

28. Casati A, Fanelli $G$, Danelli $G$, et al. Spinal anesthesia with lidocaine or preservative-free 2-chlorprocaine for outpatient knee arthroscopy: a prospective, randomized, double-blind comparison. Anesth Analg 2007; 104: 959-64.

29. Taniguchi M, Bollen AW, Drasner K. Sodium bisulfite: scapegoat for chloroprocaine neurotoxicity? Anesthesiology 2004; 100: 85-91.

30. Hiller A, Rosenberg PH. Transient neurological symptoms after spinal anaesthesia with $4 \%$ mepivacaine and $0.5 \%$ bupivacaine. Br J Anaesth 1997; 79: 301-5.
31. YaDeau JT, Liguori GA, Zayas VM. The incidence of transient neurologic symptoms after spinal anesthesia with mepivacaine. Anesth Analg 2005; 101: 661-5.

32. Salazar F, Bogdanovich A, Adalia R, Chabas E, Gomar C. Transient neurologic symptoms after spinal anaesthesia using isobaric 2\% mepivacaine and isobaric 2\% lidocaine. Acta Anaesthesiol Scand 2001; 45: 240-5.

33. Liguori GA, Zayas VM, Chisholm MF. Transient neurologic symptoms after spinal anesthesia with mepivacaine and lidocaine. Anesthesiology 1998; 88: 619-23.

34. Liu S, Chiu AA, Carpenter RL, et al. Fentanyl prolongs lidocaine spinal anesthesia without prolonging recovery. Anesth Analg 1995; 80: 730-4.

35. Singh H, Yang J, Thornton K, Giesecke AH. Intrathecal fentanyl prolongs sensory bupivacaine spinal block. Can J Anaesth 1995; 42: 987-91.

36. Pavlin DJ, Rapp SE, Polissar NL, Malmgren JA, Koerschgen M, Keyes $H$. Factors affecting discharge time in outpatients. Anesth Analg 1998; 87: 816-26. 